\title{
Suboxide characteristics in ultrathin oxides grown under novel oxidation processes
}

\author{
Yen-Po Lin and Jenn-Gwo Hwu ${ }^{\text {a) }}$ \\ Room 446, Department of Electrical Engineering, Graduate Institute of Electronics Engineering, \\ National Taiwan University, Taipei, Taiwan, R.O.C.
}

(Received 28 August 2003; accepted 26 July 2004; published 7 October 2004)

\begin{abstract}
Interfacial suboxide $\left(\mathrm{SiO}_{x}, 0<x<2\right)$ between $\mathrm{Si}$ and its stable $\mathrm{SiO}_{2}$ is observed to be a key factor to affect the ultrathin-oxide quality. $\mathrm{SiO}_{2}$ grown by anodic oxidation (anodization) or by repeated-spike oxidation (RSO) presents a better dielectric characteristic than conventional rapid-thermal oxidation (RTO). This improvement can be attributed to two reasons: (1) A thinner transition region and/or (2) more stoichiometric $\mathrm{S}-\mathrm{O}$ bonds under the same oxide thickness. Anodic $\mathrm{SiO}_{2}$ presents a thinner suboxide width (interface region) and $\mathrm{RSO} \mathrm{SiO}_{2}$ demonstrates the existence of less suboxide existence at the near-surface region (oxide bulk). The reduction of the imperfect bonding structure in suboxide gives an abrupt $\mathrm{Si}-\mathrm{SiO}_{2}$ interface and consequently, the reduction of electron tunneling probability through oxide. (C) 2004 American Vacuum Society. [DOI: 10.1116/1.1795824]
\end{abstract}

\section{INTRODUCTION}

As the dimension of silicon complementary metal-oxide semiconductor (CMOS) devices shrink further into the deepsubmicron range, ultrathin $\mathrm{SiO}_{2}$ is necessary to maintain the gate-driving current. When the oxide is thinner than $\sim 3 \mathrm{~nm}$, the dominant tunneling mechanism changes from FowlerNordheim (FN) tunneling to direct tunneling (DT). A reduction of $\sim 2 \AA$ in oxide thickness $\left(T_{\text {ox }}\right)$ leads to an order of magnitude increase in DT current, which is a problematic issue for limiting $T_{\mathrm{ox}}$ scaling. ${ }^{1}$ At the same time, the interfacial transition region's fraction becomes larger of the total oxide layer. The presence of defects in the suboxide becomes crucial to the oxide quality. These defects can function as oxide traps, oxygen vacancies, dangling bonds, and voids. These defects would lead to an increase of trap-assisted tunneling current and also the introduction of catastrophic oxide breakdown. ${ }^{2}$ Ultrathin-oxide quality is controlled by the complex combination of oxidation methods, growth kinetics, and equilibrium energies. Therefore, many studies have been proposed to enhance the ultrathin gate-oxide quality by improved growth conditions or by additional process treatments. ${ }^{3-5}$ The results reveal that the interfacial transition region is both nonstoichiometric and improvable. Furthermore, it is known that a thin and reliable $\mathrm{SiO}_{2}$ interlayer is beneficial for maintaining high interface quality and carrier mobility in future devices with high-k dielectrics. Therefore, we believe this transition region would be of great technological importance and is worthy of studying in gatedielectric engineering.

From the literature ${ }^{6,7}$ the interfacial transition region, i.e., the suboxide region $\left(\mathrm{SiO}_{x}, x<2\right)$, is composed of crystalline $\mathrm{Si}, \mathrm{SiO}_{2}$ and a high ratio of void that were formed during the competition process between $\mathrm{Si}$ monomer creation and $\mathrm{SiO}$ production. When the suboxide arrangement extends into the

\footnotetext{
a)Electronic mail: hwu@cc.ee.ntu.edu.tw
}

oxide, localized tunneling current occurs and the effective oxide thickness is reduced. Many works have been proposed to minimize the transition width, e.g., post-oxidation annealing and interfacial nitridation. The results imply that the suboxide characteristics are strongly dependent on the growth condition and the addition of process treatment.

In this work, oxides prepared by novel anodic oxidation (anodization) and repeated-spike oxidation (RSO) were examined to verify the suboxide influence. In our previous studies, ${ }^{8-11}$ it was shown that anodic and $\mathrm{RSO} \mathrm{SiO}_{2}$ exhibit improved characteristics with respect to the conventional thermally grown $\mathrm{SiO}_{2}$. Briefly, it was observed that the

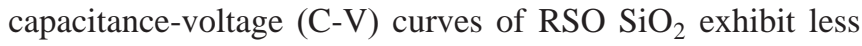
frequency response, and the anodic $\mathrm{SiO}_{2}$ presents a higher breakdown field and a lower gate-leakage current property. In this work, the layer-by-layer composition from the oxide surface to the inner $\mathrm{Si}-\mathrm{SiO}_{2}$ interface was evaluated by indepth analysis of x-ray photoelectron spectroscopy (XPS). The results demonstrate that the distribution and concentration of atoms in the suboxide are crucial to the oxide quality.

\section{EXPERIMENT}

Prior to oxidation, 3-inch p-type $\mathrm{Si}$ wafers were treated with standard wafer cleaning. To remove the native oxide, a final hydrofluoric acid (HF) dip was adopted. After cleaning, thin $\mathrm{SiO}_{2}$ with different thicknesses was grown separately by conventional rapid-thermal oxidation $\left(\mathrm{RTO} \mathrm{SiO}_{2}\right)$, anodic oxidation (anodic $\mathrm{SiO}_{2}$ ), and repeated-spike oxidation (RSO $\mathrm{SiO}_{2}$ ). For anodic $\mathrm{SiO}_{2}$ films, the wafer acts as an anode electrode. A constant electrolyzing field of $10 \mathrm{~V} / \mathrm{cm}$ was applied by using deionized (DI) water as an electrolyte. After anodization, post-anodization annealing (PAA) was treated at $850{ }^{\circ} \mathrm{C}$ in $\mathrm{N}_{2}$ ambient. For the RSO films, oxidation temperature was set to ramp up and cool down between $750{ }^{\circ} \mathrm{C}$ and $850{ }^{\circ} \mathrm{C}$ in the rapid-thermal process (RTP) system in an $\mathrm{O}_{2}$ ambient. The temperature profile is described in Sec. 


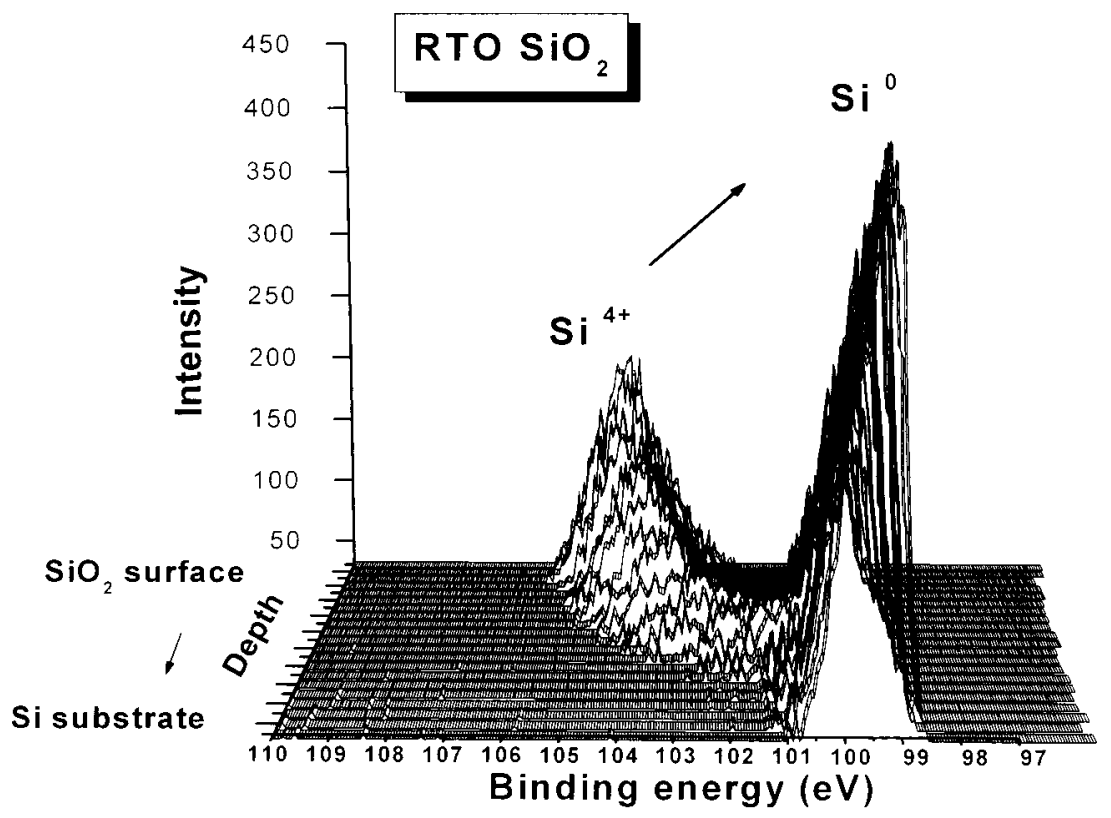

(a)

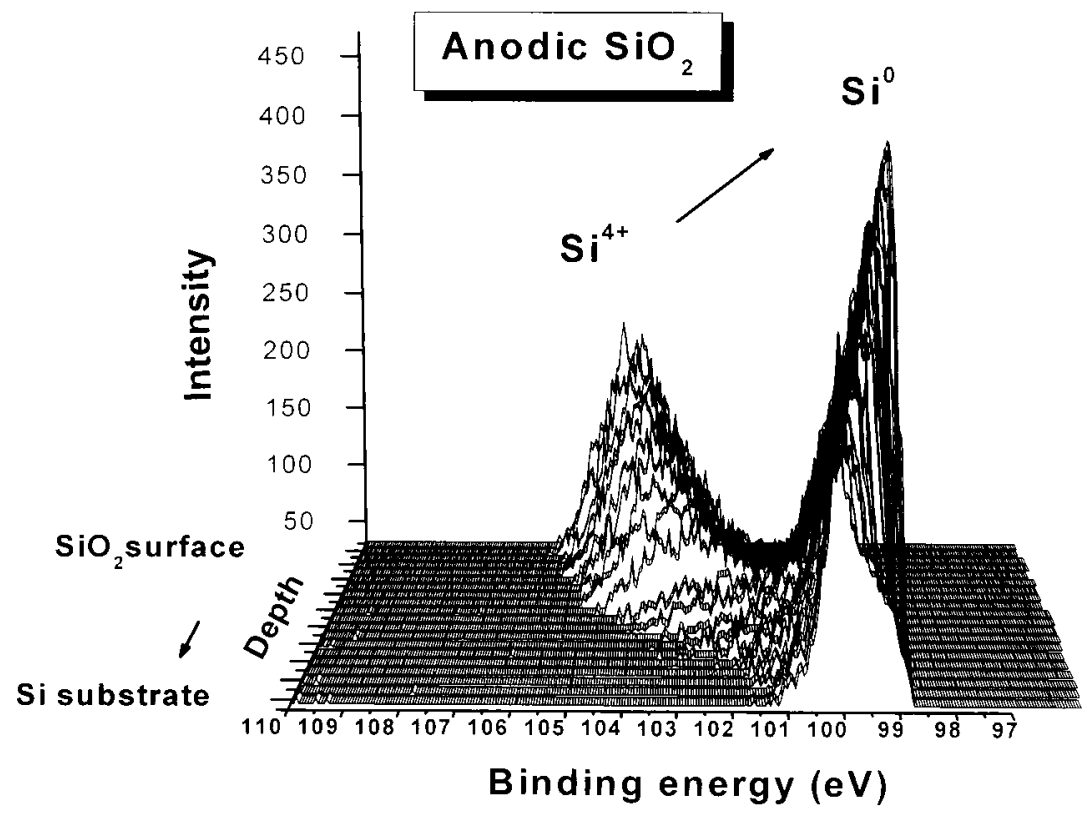

FIG. 1. Evolution of XPS Si $2 p$ spectra from the oxide surface to the $\mathrm{Si}$ substrate for oxides with $40 \AA$ thickness. These were grown by (a) typical RTO and (b) anodic oxidation. A faster spectra transformation is observed in the anodic $\mathrm{SiO}_{2}$ near the interface.

(b)

III B. For comparison, conventional $\mathrm{SiO}_{2}$ prepared by RTO at $850{ }^{\circ} \mathrm{C}$ was prepared. Finally, a metal-oxidesemiconductor (MOS) capacitor structure with an Al metal gate of $150 \mu \mathrm{m} \times 150 \mu \mathrm{m}$ was fabricated for the measurement of device characteristics. All oxides were examined by high-resolution Auger electron spectroscopy (AES) and XPS to characterize the depth profile and bonding condition, respectively. In addition, $\mathrm{C}-\mathrm{V}$ and current-voltage (I-V) measurements were utilized to analyze the electrical characteristics of ultrathin $\mathrm{SiO}_{2}$. The oxide thickness was obtained from $\mathrm{C}-\mathrm{V}$ measurement, while considering the series resistance and quantum mechanical (Q.M.) effects. ${ }^{12,13}$

\section{RESULTS AND DISCUSSION}

A. Suboxide characteristics of $\mathrm{RTO} \mathrm{SiO}_{2}$ and anodic $\mathrm{SiO}_{2}$

\section{XPS spectra and AES depth profiles of $40 \AA \mathrm{SiO}_{2}$}

Figures 1(a) and 1(b) show the XPS Si $2 p$ spectra of RTO $\mathrm{SiO}_{2}$ and anodic $\mathrm{SiO}_{2}$ with $T_{\text {ox }}=40 \AA$, respectively. The spectra were merged by each detected spectrum under various $T_{\text {ox }}$. For example, the first spectrum was detected on the oxide surface, and then a very low and constant sputter rate (by controlling the ion-gun current) was employed to remove the surface oxide (about 1.5-2 $\AA \mathrm{SiO}_{2}$ was removed for 

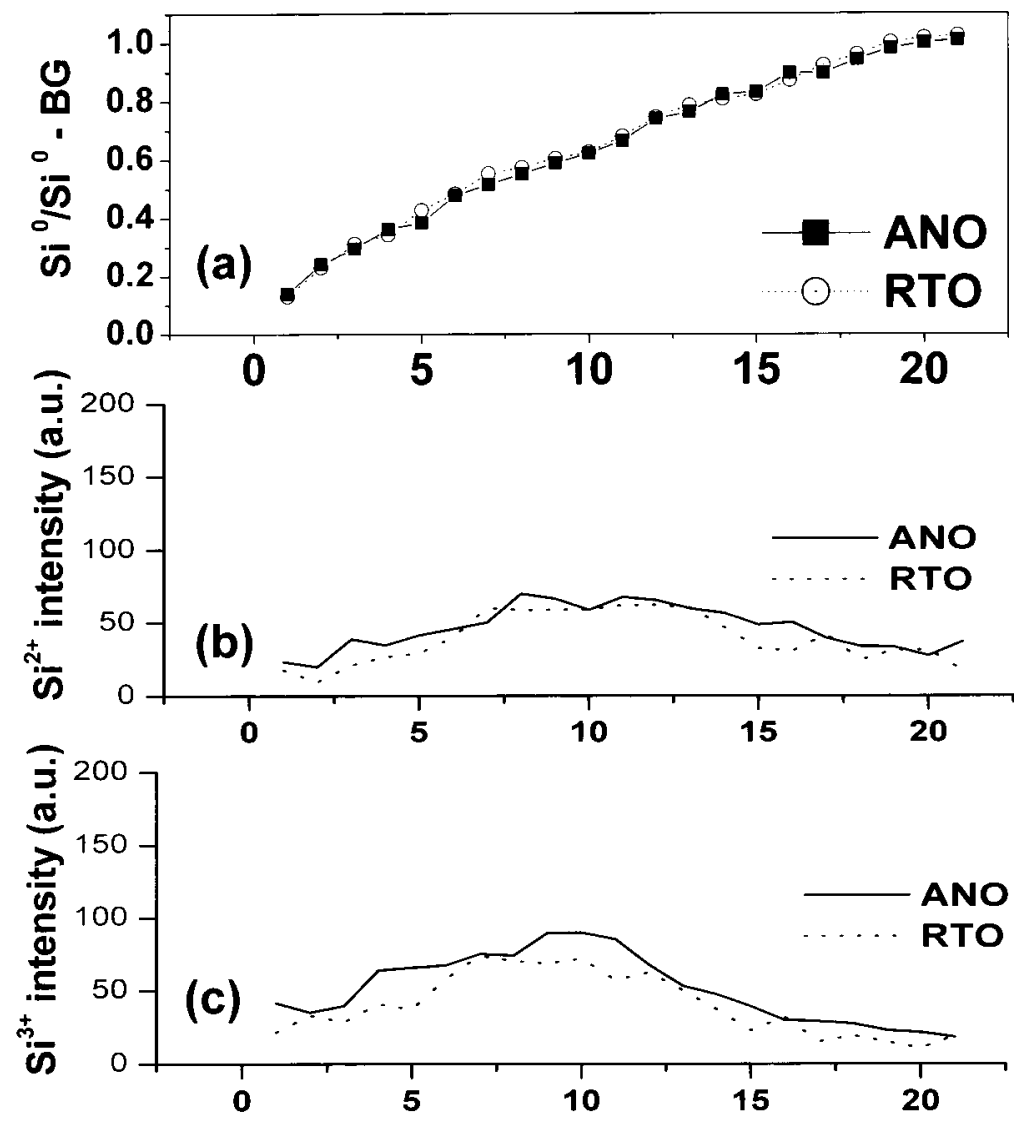

FIG. 2. (a) Intensity ratio of $\mathrm{Si}^{0}$ to the background silicon $\mathrm{Si}^{0}-\mathrm{BG}$ for $\mathrm{RTO}$ and anodic $\mathrm{SiO}_{2}$ from the surface $(\sim 0.1)$ to the substrate $(\sim 1)$ showing the sputter rate is controllable and that every $T_{\mathrm{ox}}$ is identical. In addition, XPS Si $2 p$ intensities at $\mathrm{Si}^{x+}, x=2-4$ at each step are shown in Figs. 2(b)-2(d), respectively.

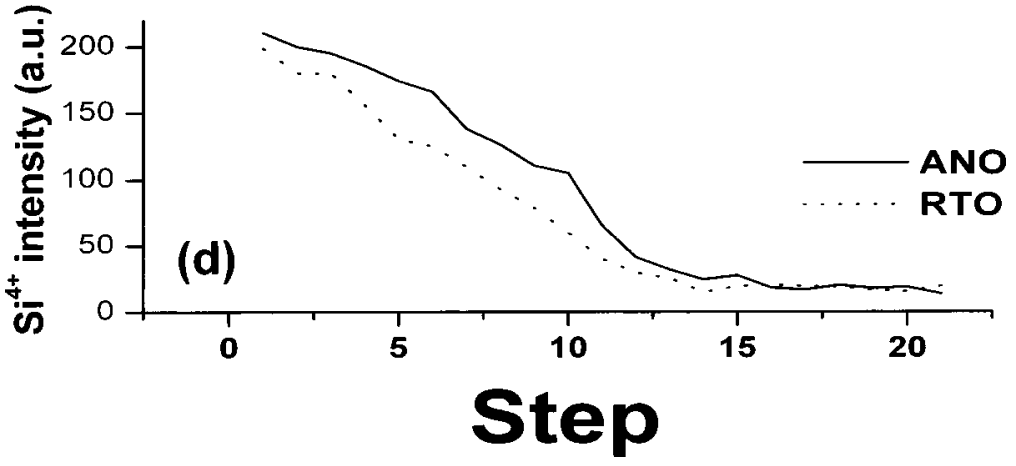

each sputter duration). After sputtering, the second spectrum was then detected. By this sequence, when the oxide layer was totally removed, only the signal from the bulk $\mathrm{Si}\left(\mathrm{Si}^{0}\right)$ could be detected. The small deviation of the standard binding energy of $99.4 \mathrm{eV}\left(\mathrm{Si}^{0}\right.$, bulk $\left.\mathrm{Si}\right)$ that occurred on each spectrum may be attributed to a residual charge on the film. However, the deviation does not affect the binding energy of the intermediate-oxidation states relative to the bulk $\mathrm{Si}\left(\mathrm{Si}^{0}\right)$. During the sequential sputtering, more suboxide might be created on the surface region and localized nonuniform etching might take place on the bombarded area. However, because the sputter rate is quite low, signals come from the $10 \mathrm{~nm}$ layer below the surface and the near-surface region (5-8 $\AA$ ) contribute to the main intensity. Hence, we think the bombardment-induced surface damage would not create a noticeable effect on the final XPS spectrum.
The stoichiometric $\mathrm{SiO}_{2}\left(\mathrm{Si}^{4+}\right)$ and $\mathrm{Si}\left(\mathrm{Si}^{0}\right.$, bulk $\left.\mathrm{Si}\right)$ spectra correspond to distinguishable binding energies of 103.3 and $99.4 \mathrm{eV}$, respectively, and the peaks among $\mathrm{Si}^{4+}$ and $\mathrm{Si}^{0}$ can be attributed to the intermediate oxidation states. By inspecting the spectra from the $\mathrm{SiO}_{2}$ surface to the $\mathrm{Si}$ substrate, it can be seen that the peaks gradually shift and transform from $\mathrm{Si}^{4+}$ to $\mathrm{Si}$. Also, it is obvious that the suboxide distributes mainly around the interface. In contrast to the anodic $\mathrm{SiO}_{2}$ spectra, a smoother transformation from $\mathrm{Si}^{4+}$ to $\mathrm{Si}$ is observed for the RTO $\mathrm{SiO}_{2}$ spectra when the spectrum gets close to the interface. It reveals the greater existence of suboxide in the RTO $\mathrm{SiO}_{2}$. The faster transformation of anodic $\mathrm{SiO}_{2}$ infers the more abrupt $\mathrm{Si}-\mathrm{SiO}_{2}$ interface.

Interpretation of the suboxide states has been widely discussed. ${ }^{14-16}$ In spite of the impurity disturbance, changes in peak intensity provide a crude means of suboxide distri- 


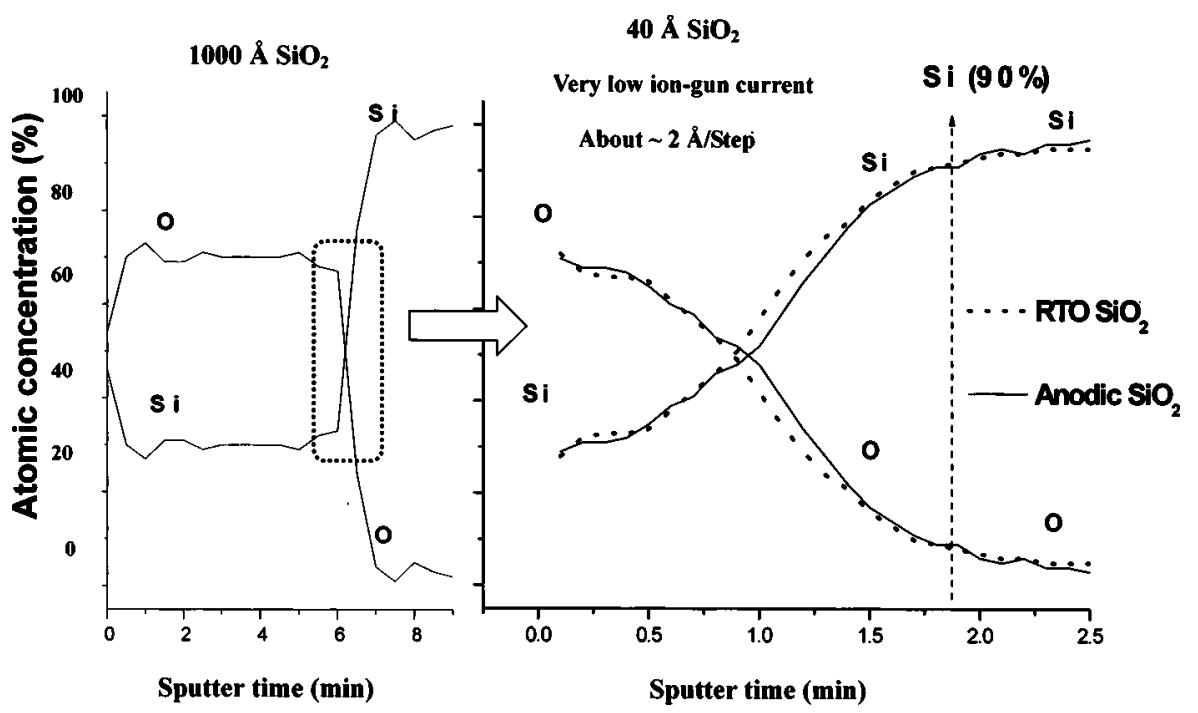

FIG. 3. AES depth profiles of (a) $1000 \AA \mathrm{SiO}_{2}$ and (b) $40 \AA \quad \mathrm{SiO}_{2}$ grown by RTO and anodic oxidations. Very low ion-gun current is used for sputtering of $40 \AA \mathrm{SiO}_{2}(\sim 2 \AA /$ step). Steeper distribution slope is observed in the $40 \AA$ anodic $\mathrm{SiO}_{2}$.

(a)

(b)

bution. From previous study, ${ }^{14}$ the $\mathrm{Si} 2 p$ spectrum can be deconvoluted to five admitted bonding configurations, i.e., $\mathrm{Si}^{x+} x=0-4$ at $99.4,100.4,101.2,102.1$, and $103.3 \mathrm{eV}$, respectively. From Fig. 1, it can be seen that when oxide was totally removed, the $\mathrm{Si}^{0}$ signal from the substrate presents a constant value, which can be referred to as substrate background $\left(\mathrm{Si}^{0}-\mathrm{BG}\right)$. As shown in Fig. 2(a), we can see the slopes of $\mathrm{Si}^{0} / \mathrm{Si}^{0}-\mathrm{BG}$ of RTO and anodic $\mathrm{SiO}_{2}$ were fairly overlapped from step 1 (surface) to step 20 (substrate). That overlap implies the sputter rate is quite controllable and the oxide thicknesses are the same for this comparison. In Figs. 2(b) and 2(c), we can see that the XPS intensities of $\mathrm{Si}^{2+}$ and $\mathrm{Si}^{3+}$ exhibit similar distributions from the oxide surface to the interface. However, in Fig. 2(d), the anodic $\mathrm{SiO}_{2}$ shows a relative steeper slope in $\mathrm{Si}^{4+}$ distribution than $\mathrm{RTO} \mathrm{SiO}_{2}$. This reveals the greater stoichiometric $\mathrm{Si}^{4+}$ existence around the $\mathrm{SiO}_{2}-\mathrm{Si}$ interface. In the suboxide region, the lack of oxygen leads to the presence of dangling bonds and traps. We suppose that unlike the RTO $\mathrm{SiO}_{2}$ grown by the interaction of high-kinetic and massive oxygen, anodic $\mathrm{SiO}_{2}$ is formed by the reaction of $\mathrm{OH}^{-}$and $\mathrm{Si}$ at room temperature. Layer by layer, the low-kinetic oxidant reacts with the silicon. At that time, the oxygen vacancies are easier to compensate. Therefore, we believe incorporating more oxygen in the film is helpful for reducing the imperfect suboxide bonding.

Furthermore, depth profiles of RTO $\mathrm{SiO}_{2}$ and anodic $\mathrm{SiO}_{2}$ were detected by high-resolution AES. The atomic concentration of $1000 \AA \mathrm{SiO}_{2}$ shown in Fig. 3(a) presents a quite stoichiometric proportion of $\mathrm{Si}$ and $\mathrm{O}(1: 2)$ in the bulk. On the right side, depth profiles of RTO $\mathrm{SiO}_{2}$ and anodic $\mathrm{SiO}_{2}$ with $T_{\text {ox }}=40 \AA$ are shown in Fig. 3(b). By controlling the ion-gun current ( $\sim 2 \AA$ per step), the anodic $\mathrm{SiO}_{2}$ demonstrated a relatively steeper profile that implies two contributions: (i) A thinner transition region between $\mathrm{SiO}_{2}-\mathrm{Si}$ and (ii) a higher stoichiometric $\mathrm{SiO}_{2}$ fraction under the same $T_{\mathrm{ox}}$. Here, we can see this result is identical to the previous XPS analysis.

\section{Electrical characteristics of anodic and $\mathrm{RTO} \mathrm{SiO}_{2}$}

Gate-leakage current density of RTO and anodic $\mathrm{SiO}_{2}$ versus $T_{\mathrm{ox}}$ ranging from 18 to $30 \AA$ (gate bias at $V_{\mathrm{G}}-V_{\mathrm{FB}}$ $=-1 \mathrm{~V}$ ) is shown in Fig. 4. In this work, high-frequency $\mathrm{C}-\mathrm{V}$ curves of $100 \mathrm{~K}$ and $1 \mathrm{MHz}$ were measured and corrected to eliminate the series-resistance effect. ${ }^{12}$ Afterward, the two frequency-corrected $\mathrm{C}-\mathrm{V}$ curve was taken to fit the quantum mechanical (Q.M.)-considered C-V curves to obtain the $T_{\mathrm{ox}}{ }^{13}$ Under the same $T_{\mathrm{ox}}$, we can see that the leakage current of the anodic $\mathrm{SiO}_{2}$ presents an order of magnitude lower than that of $\mathrm{RTO} \mathrm{SiO}_{2}$. This indicates that a thinner transition

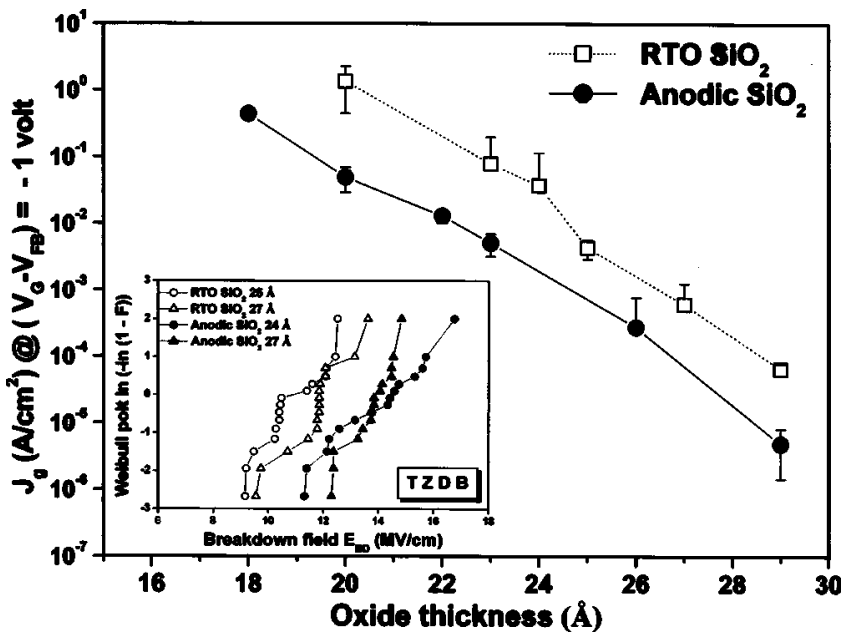

FIG. 4. Gate leakage current densities versus oxide thickness of RTO and anodic $\mathrm{SiO}_{2}$ with a gate bias of $V_{\mathrm{G}}-V_{\mathrm{FB}}=-1 \mathrm{~V}$. Weibull plot of TZDB characteristic for RTO and anodic $\mathrm{SiO}_{2}$ samples is shown in the inset. 


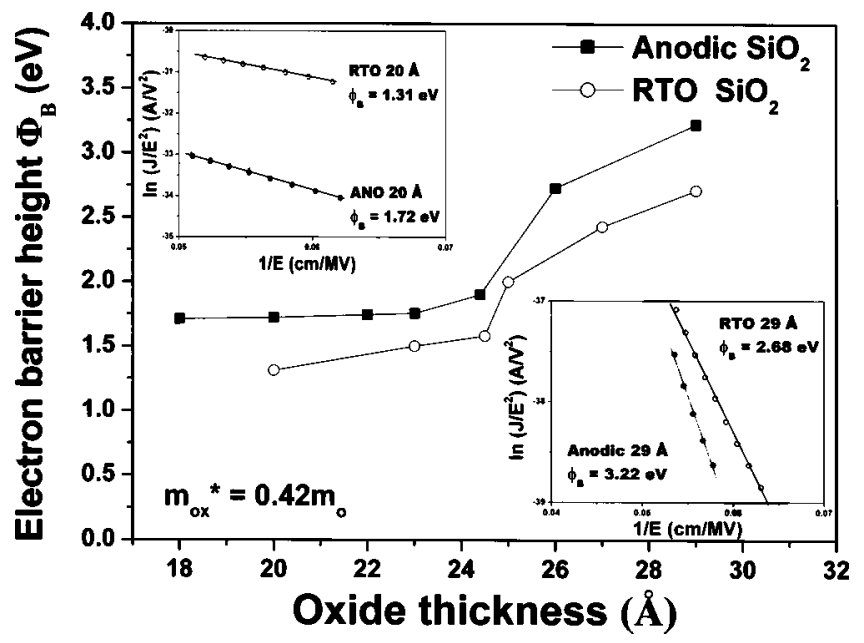

FIG. 5. Electron-barrier height $\left(\Phi_{\mathrm{B}}\right)$ versus the oxide thickness for RTO and anodic oxides. As shown in the inset, each $\Phi_{\mathrm{B}}$ is extracted from FN plots.

region can effectively reduce the tunneling probability of electrons through oxide. The time-zero dielectric breakdown (TZDB) shown in the inset illustrates that to break down an anodic $\mathrm{SiO}_{2}$ could require a field $\sim 2 \mathrm{MV} / \mathrm{cm}$ higher than RTO $\mathrm{SiO}_{2}$. One may wonder if more $\mathrm{OH}$ bonds in the anodic oxide would cause a difference of interfacial $\mathrm{Al}_{2} \mathrm{O}_{3}$ between the $\mathrm{Al}$ gate and $\mathrm{SiO}_{2}$. Our previous study found that most of the hydrogen in the anodic film could be removed after the subsequent annealing process and the excess oxygen may react with the silicon or be evaporated from the film. Therefore, if the subsequent annealing temperature is high enough to remove the excess $\mathrm{OH}$ bonds, we think the variation might be suppressed. From this result, it is believed that the lessextended suboxide in anodic $\mathrm{SiO}_{2}$ is responsible for the higher endurance observed in the breakdown field.

Fowler-Nordheim (FN) conduction is well known as one of the $\mathrm{SiO}_{2}$ tunneling mechanisms. Many studies have been devoted to the tunneling regime. ${ }^{17,18}$ The potential barrier height $\left(\Phi_{\mathrm{B}}\right)$ is the most important parameter in this conduction. From the FN model, $\Phi_{\mathrm{B}}$ can be evaluated from the I-V measurement. However, in such a thin oxide region, the DT effects become impossible to ignore. The emergence of the DT current $\left(J_{\mathrm{DT}}\right)$ leads to the lowering of effective $\Phi_{\mathrm{B}}$. However, while the suboxide extends into the film, localized tunneling enhances the $J_{\mathrm{DT}}$ that leads to the more severe lowering of $\Phi_{\mathrm{B}}$. Therefore, effective $\Phi_{\mathrm{B}}$ extracted from the FN model can provide the suboxide information. Besides, when Bell et al. comprehensively researched $\mathrm{SiO}_{x} \quad(0<x<2)$ alloys, ${ }^{19}$ the bandgap value was found to be proportional to the oxygen-incorporation level. This result is in consensus with the $\Phi_{\mathrm{B}}$ lowering phenomenon shown in Fig. 5. Effective $\Phi_{\mathrm{B}}$ between the metal gate and $\mathrm{SiO}_{2}$ is obtained from the FN tunneling formula of the slope of $\ln \left(\mathrm{JF}^{-2}\right)$ vs $\mathrm{F}^{-1}$ as shown in the insets, where $J$ is the $\mathrm{FN}$ tunneling-current density and $F$ is the oxide field. As shown, $1.5 \mathrm{eV}$ decreased in $\Phi_{\mathrm{B}}$ is observed for both samples when $T_{\mathrm{ox}}$ decreased from 30 to $20 \AA$. This experimental evidence explains the bandgap roll-off phenomenon when $T_{\mathrm{ox}}$ scales into the DT region.
SiOx, $0<x<2$
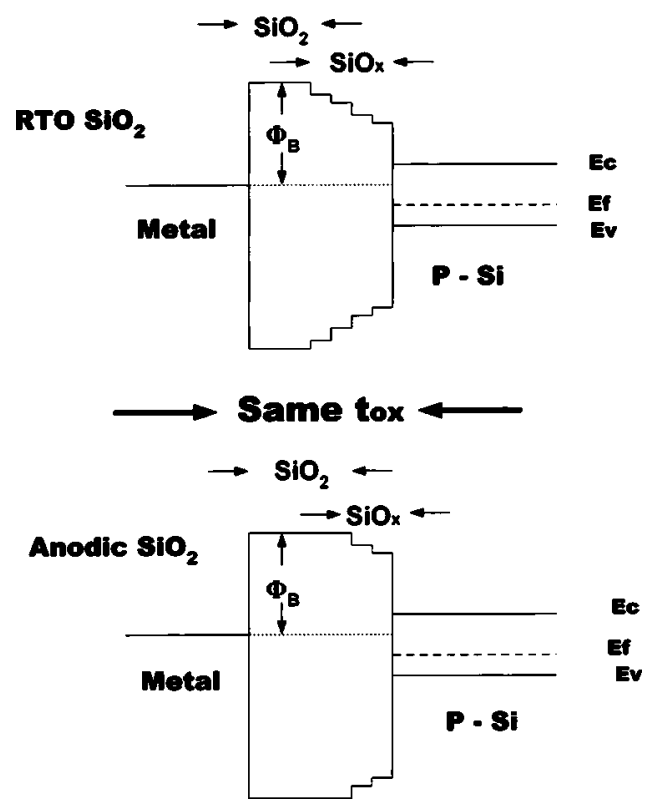

FIG. 6. Schematic diagram of suboxide-induced bandgap lowering of RTO and anodic $\mathrm{SiO}_{2}$. The lower bandgap is employed at the region where suboxide exists.

Here, anodic $\mathrm{SiO}_{2}$ still retains a higher $\Phi_{\mathrm{B}}$ than $\mathrm{RTO} \mathrm{SiO}_{2}$ under the same $T_{\mathrm{ox}}$. It is reasonable to assume that when the DT effect becomes less important, the oxide grown by RTO and anodic oxidation should have identical $\Phi_{B}$. However, in our previous study, anodic $\mathrm{SiO}_{2}$ exhibited properties of lower gate-leakage current and higher $\Phi_{\mathrm{B}}$ than the thermally grown $\mathrm{SiO}_{2}$ in thicker region. When $\mathrm{FN}$ tunneling dominates the gate-tunneling current, fewer tunneling paths through the oxide would keep an ideal $\Phi_{\mathrm{B}}$ value. We think the greater suboxide existence in the bulk could provide more tunneling paths, i.e., trap-assisted tunneling. Anodic $\mathrm{SiO}_{2}$ maintains higher effective $\Phi_{\mathrm{B}}$ than RTO $\mathrm{SiO}_{2}$ under the same oxide thickness. This can be attributed to less suboxide. The less suboxide that exists in the bulk oxide would effectively reduce the probability of trap-assisted tunneling, thus the higher $\Phi_{\mathrm{B}}$ is observed in anodic $\mathrm{SiO}_{2}$.

Here we propose a schematic diagram to describe the suboxide-induced $\Phi_{\mathrm{B}}$ lowering phenomenon shown in Fig. 6. The suboxide region exhibits a lower conduction-band offset than stoichiometric oxide based on the XPS results. ${ }^{4}$ The lower bandgap profile is employed to separate the suboxide region from the stoichiometric region. The more oxygen incorporated in the anodic $\mathrm{SiO}_{2}$, the more perfect the bandgap profile. According to the Deal-Grove model, the diffusive flux is dominated by the interface reaction in the thin-oxide regime. Hence a low and stable interface reaction is important during oxidation. Standard techniques such as RTO will have difficulty in producing such a short transition width. This difficulty is due to the high-kinetic $\mathrm{O}$ mass generated during the slow ramp-up time. Anodic $\mathrm{SiO}_{2}$, grown by fieldenhanced oxidation layer by layer, presents a thinner transition region than $\mathrm{RTO} \mathrm{SiO}_{2}$. 

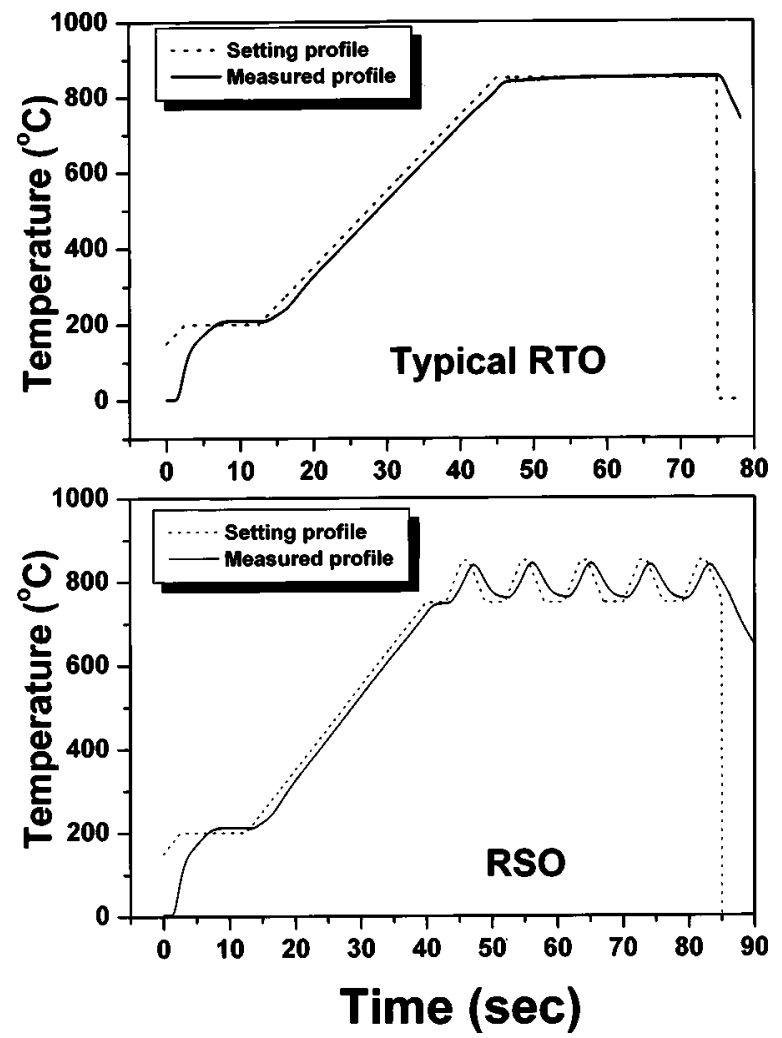

FIG. 7. Setting and measured temperature profiles of (a) typical RTO and (b) RSO.

\section{B. Suboxide characteristics of $\mathrm{RTO}^{\mathrm{SiO}_{2}}$ and RSO $\mathrm{SiO}_{2}$}

In addition to the anodic $\mathrm{SiO}_{2}$, our previous works also revealed that $\mathrm{SiO}_{2}$ prepared by RSO exhibits better electrical characteristic than RTO $\mathrm{SiO}_{2}{ }^{11}$ The temperature profiles of RTO and RSO are shown in Figs. 7(a) and 7(b), respectively. In Fig. 7(a), the oxidation temperature was kept at $850{ }^{\circ} \mathrm{C}$, and in Fig. 7(b), the temperature profile was set to vibrate from $750{ }^{\circ} \mathrm{C}$ to $850{ }^{\circ} \mathrm{C}$. In our previous work, it was found that by using RSO technology the absorption of the radiated heat in two different temperature zones could be compensated on a wafer to form a more uniform oxide. ${ }^{10}$ The better uniformity in $T_{\text {ox }}$ could effectively reduce the probability of local-oxide thinning. Thereby, it is believed that when temperature ramps up and cools down within a short time, the residual atomic oxygen in the oxide layer has a greater chance to fill the silicon dangling bonds.

For the same reason, we believe the suboxide has played a major role in improving of the RSO technique. To sustain this supposition, the same procedure is utilized to examine the suboxide distribution, as shown in Fig. 8. Figures 8(a) and 8(b) show the XPS spectra of RTO $\mathrm{SiO}_{2}$ and RSO $\mathrm{SiO}_{2}$ with $T_{\text {ox }}=40 \AA$, respectively. Unlike the anodic $\mathrm{SiO}_{2}$ spectra shown in Fig. 1, the RSO spectrum does not show a distinct difference in the interface-spectrum transformation. However, under the same $T_{\text {ox }}$, the ratio of $\mathrm{Si}^{4+}-\mathrm{Si}^{0}$ is observed to exhibit a relatively higher value for the $\mathrm{RSO} \mathrm{SiO}_{2}$ on the surface. In the same sequence, when oxide was totally re-

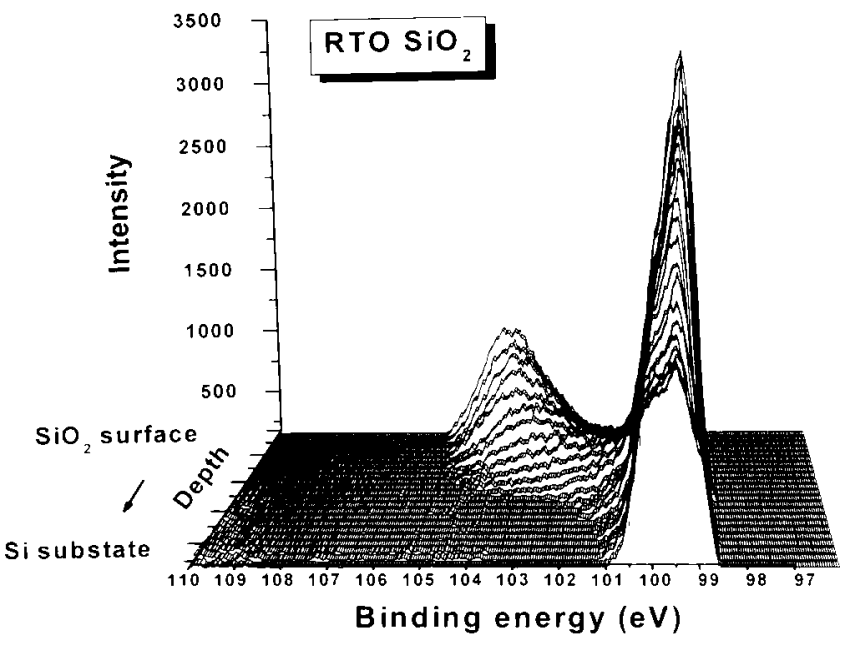

(a)

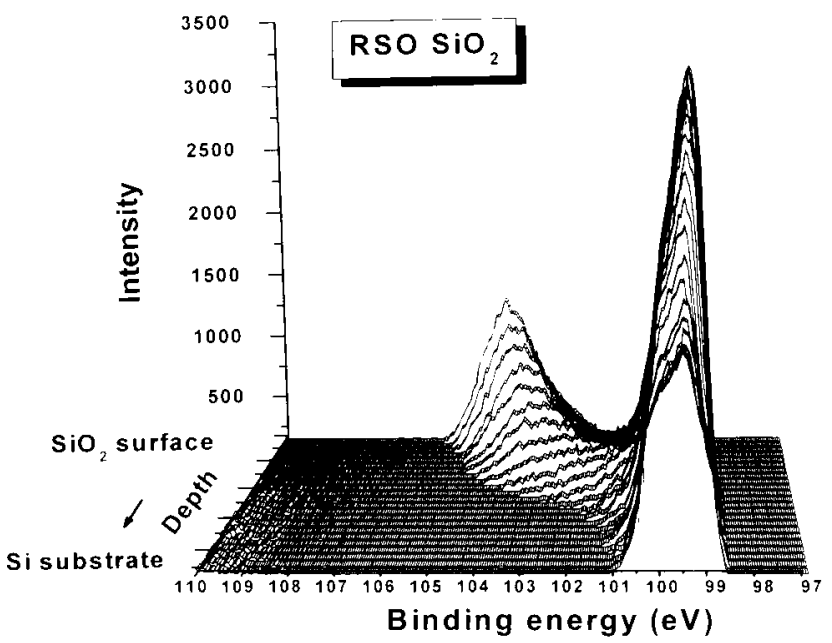

(b)

FIG. 8. Evolution of XPS Si $2 p$ spectra from the oxide surface to the $\mathrm{Si}$ substrate for oxides with $40 \AA$ thickness. These were grown by (a) typical RTO and (b) RSO. The RSO $\mathrm{SiO}_{2}$ exhibits a relatively higher $\mathrm{Si}^{4+}-\mathrm{Si}^{0}$ intensity value on the surface under the same $T_{\mathrm{ox}}$.

moved, we refer to the constant $\mathrm{Si}^{0}$ intensity as $\mathrm{Si}^{0}$-BG. As shown in Fig. 9(a), the curves of $\mathrm{Si}^{0}-\mathrm{Si}^{0}-\mathrm{BG}$ are shifted to become fairly overlapped from step 1 (surface) to step 22 (substrate) to make sure that the oxide thicknesses are identical in this comparison. Relative intensity ratios of $\mathrm{Si}^{x+}-\mathrm{Si}^{0}$, $x=2-4$ at each step are shown in Figs. 9(b)-9(d), respectively. Unlike anodic $\mathrm{SiO}_{2}$, it is obvious that the $\mathrm{RSO} \mathrm{SiO}_{2}$ exhibits less suboxide component at the near-surface region [Figs. 9(b) and 9(c)]. However, the intensity of $\mathrm{Si}^{4+}$ [Fig. 9(d)] shows more stoichiometric bonding existence at the near-surface region (oxide bulk) in the $\mathrm{RSO} \mathrm{SiO}_{2}$. This evidence apparently validates the previous assumption. During the temperature vibration, the reactive residual $\mathrm{O}$ has more chance to compensate the imperfect $\mathrm{Si}-\mathrm{O}$ arrangement. The residual oxygen captured by the dangling bonds results in a more stoichiometric $\mathrm{Si}-\mathrm{O}$ network. Thus the lower gate leakage can be observed in Fig. 10. RSO $\mathrm{SiO}_{2}$ shows approximately one order of magnitude lower gate leakage than RTO $\mathrm{SiO}_{2}$. 

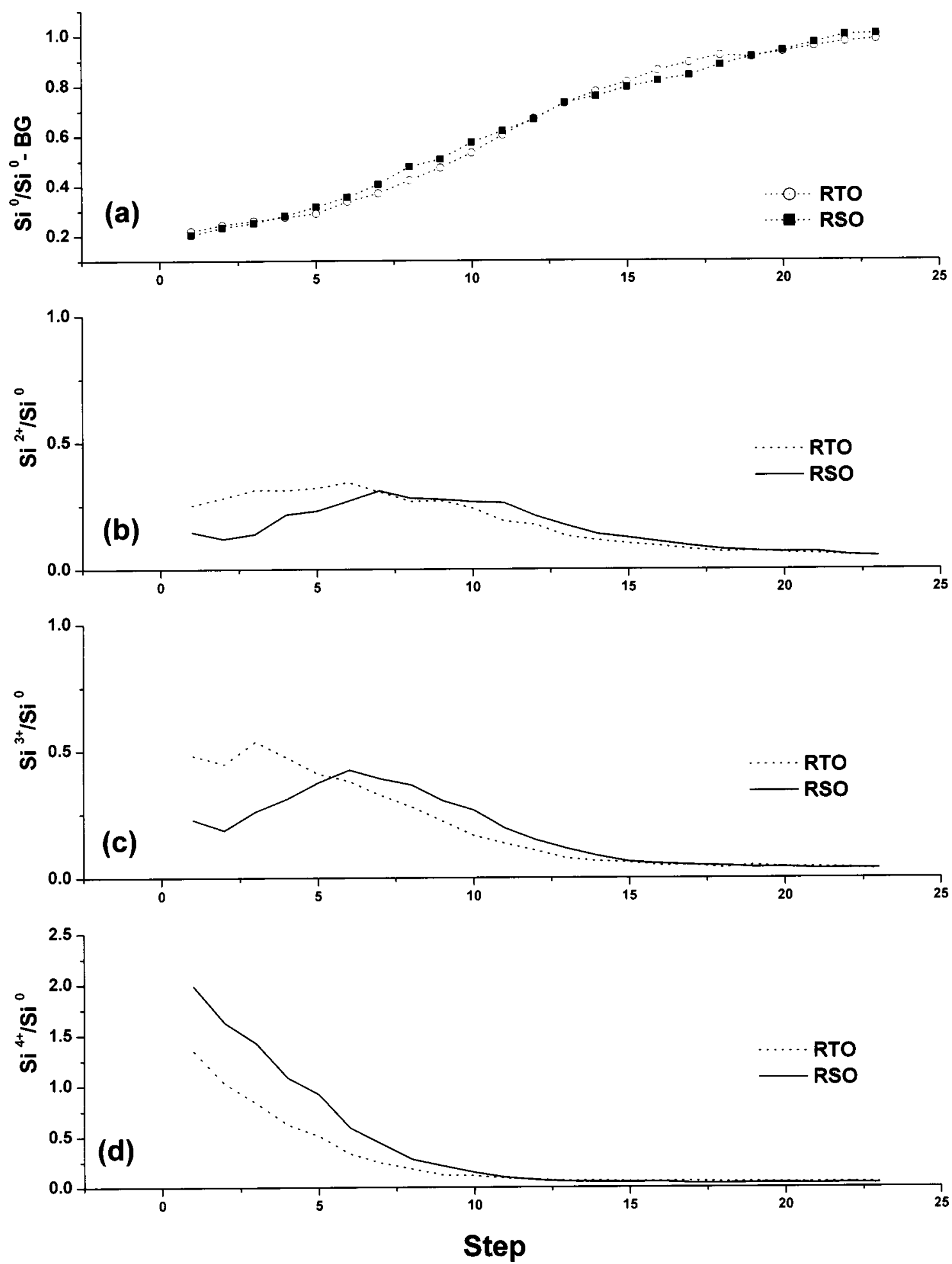

FIG. 9. XPS intensity ratios of (a) $\mathrm{Si}^{0}-\mathrm{Si}^{0}-\mathrm{BG}$, (b) $\mathrm{Si}^{2+}-\mathrm{Si}^{0}$, (c) $\mathrm{Si}^{3+}-\mathrm{Si}^{0}$, and (d) $\mathrm{Si}^{4+}-\mathrm{Si}^{0}$ evaluated from surface (step 0) to silicon substrate (step 22). In (a), the constant intensity from bulk $\mathrm{Si}$ is referred to as $\mathrm{Si}^{0}-\mathrm{BG}$, curves of the intensity ratio $\left(\mathrm{Si}^{0}-\mathrm{Si}^{0}-\mathrm{BG}\right)$ from the surface $(\sim 0.1)$ to the substrate $(\sim 1)$ show

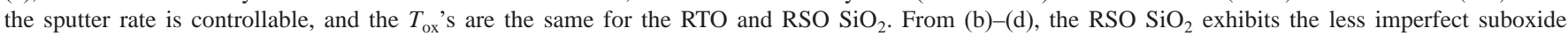
$\left(\mathrm{Si}^{2+}, \mathrm{Si}^{3+}\right)$ and more stoichiometric oxide $\left(\mathrm{Si}^{4+}\right)$ at the near-surface region.

From the above discussion, XPS provides strong evidence to verify the reduction of suboxide in $\mathrm{RSO} \mathrm{SiO}_{2}$. Compared to the anodic $\mathrm{SiO}_{2}$, we can see that the different growth conditions could cause variations in suboxide distribution. The more stoichiometric $\mathrm{Si}-\mathrm{O}$ fraction accounts for the better insulator characteristics.

\section{CONCLUSIONS}

In this work, suboxide characteristics are widely studied under different oxidation procedures. We found that the oxidation methods and the reaction kinetics greatly affect the suboxide distribution and concentration. From the layer-by- 


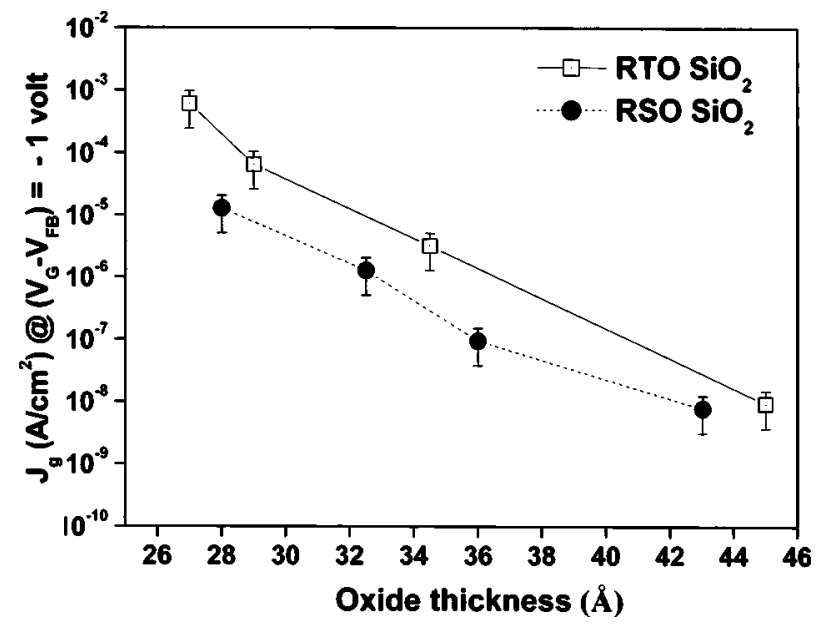

FIG. 10. Gate leakage current densities versus oxide thickness of RTO and RSO $\mathrm{SiO}_{2}$ with a gate bias of $V_{\mathrm{G}}-V_{\mathrm{FB}}=-1 \mathrm{~V}$.

layer composition analyses, we see that field-enhanced oxidation produces a thinner suboxide transition width for anodic $\mathrm{SiO}_{2}$. We may attribute this finding to the low and stable reaction of silicon and oxidant under room temperature. In another aspect, $\mathrm{SiO}_{2}$ prepared by $\mathrm{RSO}$ was examined in the same sequence to verify our previous supposition. It is supposed that temperature vibration can provide the high-kinetic $\mathrm{O}$ with more residual time to fill the suboxide dangling bonds. The gate-insulator property is strongly dependent on the oxide stoichiometry. The anodic $\mathrm{SiO}_{2}$ exhibits a thinner transition region and the $\mathrm{RSO} \mathrm{SiO}_{2}$ exhibits a morestoichiometric bulk oxide. Consequently, we believe that as oxide thickness is continuously reduced, the understanding of the suboxide and the control of its distribution will become a major issue in gate-dielectric engineering.

\section{ACKNOWLEDGMENT}

The authors thank the National Science Council of the Republic of China for supporting this work under Contract No. NSC-92-2215-E-002-005.

${ }^{1}$ B. Brar, G. D. Wilk, and A. C. Seabaugh, Appl. Phys. Lett. 69, 2728 (1996).

${ }^{2}$ C. T. Liu, A. Ghetti, Y. Ma, G. Alers, C. P. Chang, J. I. Colonell, W. Y. C. Lai, C. S. Pai, R. Liu, H. Vaidya, and J. T. Clemens, IEDM Technical Dig. 85 (1997).

${ }^{3}$ G. D. Wilk and B. Brar, IEEE Electron Device Lett. 20, 132 (1999).

${ }^{4}$ H. Yang, H. Niimi, J. W. Keister, and G. Lucovsky, IEEE Electron Device Lett. 21, 76 (2000)

${ }^{5}$ G. Lucovsky, A. Banerjee, B. Hinds, B. Claflin, K. Koh, and H. Yang, J. Vac. Sci. Technol. B 15, 1074 (1997).

${ }^{6}$ T. J. Maloney, D. E. Aspnes, H. Arwin, and T. W. Sigmon, Appl. Phys. Lett. 44, 517 (1984).

${ }^{7}$ Y. Wei, R. M. Wallace, and A. C. Seabaugh, Appl. Phys. Lett. 69, 1270 (1996).

${ }^{8}$ M. J. Jeng and J. G. Hwu, Appl. Phys. Lett. 69, 3875 (1996).

${ }^{9}$ Y. C. Chen, C. Y. Lee, and J. G. Hwu, Solid-State Electron. 45, 1531 (2001).

${ }^{10}$ C. C. Hong, C. Y. Lee, Y. L. Hsieh, C. C. Liu, I. K. Fong, and J. G. Hwu, IEEE Trans. Semicond. Manuf. 14, 227 (2001).

${ }^{11}$ C. C. Hong, C. Y. Chang, C. Y. Lee, and J. G. Hwu, IEEE Electron Device Lett. 23, 28 (2002)

${ }^{12}$ K. J. Yang and C. Hu, IEEE Electron Device Lett. 46, 1500 (1999).

${ }^{13}$ K. Yang, Y. C. King, and C. Hu, Tech. Digest VLSI Symp. 77 (1999).

${ }^{14}$ K. T. Queeney, M. K. Weldon, J. P. Chang, Y. J. Chabal, A. B. Gurevich, and J. Sapjeta, J. Appl. Phys. 87, 1322 (2000).

${ }^{15}$ F. J. Himpsel, F. R. Mcfeely, A. Taleb-Ibrahimi, and J. A. Yarmoff, Phys. Rev. B 38, 6084 (1988)

${ }^{16}$ T. Hattori, J. Vac. Sci. Technol. B 11, 1528 (1993).

${ }^{17}$ S. Horiguchi and H. Yoshino, J. Appl. Phys. 58, 1597 (1985).

${ }^{18}$ J. Maserjian and N. Zamani, J. Appl. Phys. 53, 559 (1982).

${ }^{19}$ F. G. Bell and L. Ley, Phys. Rev. B 37, 8383 (1988). 